\title{
A EMENDA CONSTITUCIONAL N. 29 DE 2000 E OS GOVERNOS ESTADUAIS*
}

Fátima Beatriz Fortes

Este artigo analisa os efeitos da Emenda Constitucional n. 29, de 2000 (EC n. 29), nas decisões alocativas dos governadores estaduais relativas aos gastos com saúde.

A EC n. 29 tem por objetivo "assegurar os recursos mínimos para o financiamento das ações e serviços públicos de saúde". Para tanto, determinou que os estados deveriam gastar, até 2004, no mínimo 12\% de suas receitas de impostos e transferências constitucionais com assistência à saúde. Para os municípios, o percentual seria de $15 \%$. A EC n. 29 estabeleceu ainda, para os estados e os municípios, o percentual mínimo de $7 \%$ em 2000 e determinou que a diferença entre o percentual aplicado naquele ano e o estipulado para 2004 deveria ser reduzida à razão anual de um quinto. Para a União, não foi estipulado percentual, mas definiu-se que a evolução de seus gastos com saúde

\footnotetext{
Este artigo apresenta os resultados de minha tese de doutorado (Fortes, 2009). Agradeço, mais uma vez, aos membros da banca: Fátima Anastasia (orientadora), José Francisco Soares (coorientador), Carlos Ranulfo Melo, Celina Souza, Magna Inácio e Renato Boschi.
} 
deveria acompanhar a variação do Produto Interno Bruto (PIB). Ainda de acordo com essa emenda, os percentuais mínimos da receita das três esferas de governo, que deveriam ser gastos com saúde a partir de 2005, seriam definidos por Lei Complementar. Na ausência de tal lei, a EC n. 29 estabelece que prevalecem os critérios definidos para 2004 (Brasil, 2000).

A EC n. 29 institui, dessa forma, a responsabilização de todos os entes federados para com o financiamento do Sistema Único de Saúde (SUS), de modo a enfrentar os sérios problemas de insuficiência e irregularidade de recursos financeiros vivenciados ao longo da década de 1990.

Com relação especificamente aos gastos dos estados e do Distrito Federal (DF) com saúde, a comparação entre os períodos anterior e posterior à EC n. 29 sugere que a iniciativa foi bem-sucedida em elevar o comprometimento dos recursos próprios com a saúde. De fato, após a EC 168 n. 29 a grande maioria dos estados aumentou o percentual da receita aplicado na saúde, diferentemente do que se observou na década anterior. Constatou-se também que o comportamento dos estados variou de modo significativo, apresentando desde um decréscimo de $42 \%$ dos recursos destinados à saúde, na Paraíba, a uma elevação de $307 \%$, no Maranhão. Os fatos de alguns estados terem reduzido o percentual da receita aplicado na saúde, quando deveriam tê-lo aumentado, de poucos estados terem conseguido atingir o percentual de $12 \%$ em 2004 e de a implementação da EC n.29 não ter se dado de forma gradual como estipulado sugerem que outros fatores influenciaram as escolhas alocativas dos governadores.

Partindo-se dos pressupostos de que as instituições orientam as preferências e os cálculos dos atores e que, em contextos distintos, as mesmas regras podem ter efeitos diferentes no comportamento dos atores (Thelen e Steinmo, 1992; Weaver e Rockman, 1993; Putnam, 1996; Tsebelis, 
1998; Anastasia, 2002), duas indagações orientaram a investigação: 1) Quais os efeitos da EC n. 29 nas decisões alocativas dos governadores estaduais relativas aos gastos com saúde? 2) Por que os entes federativos se diferenciam no tocante à implementação da EC n. 29?

A discussão proposta relaciona-se, portanto, a duas das questões analíticas tratadas pela literatura do novo institucionalismo. Em primeiro lugar, trata-se de verificar como as instituições "importam", o que, no caso da EC n. 29, significa identificar as respostas dos governos estaduais. Em segundo lugar, trata-se de analisar a influência do contexto nas respostas dos governadores, de modo a propor uma explicação para as diferenças encontradas. Conforme indicam Puttman e López-Acuna (apud Viana et al., 2006), mesmo reconhecendo que a relação condicionantes/ tomada de decisões seja extremamente complexa [...]", o pressuposto é o de que, a partir da associação entre as variáveis selecionadas para descrever a situação em que se deram escolhas e as respostas dos governadores em termos do percentual da receita aplicado em ações e serviços de saúde, seja possível responder à indagação proposta.

Este artigo está organizado em cinco seções, além desta introdução. A primeira aborda as origens da EC n. 29. A segunda trata do processo de regulamentação dessa emenda. A terceira apresenta as variáveis selecionadas para diferenciar os estados em termos do contexto das escolhas dos governadores. Na quarta, é feita a verificação empírica dos efeitos da EC n. 29 nas escolhas alocativas dos governos estaduais. A quinta apresenta as conclusões do estudo.

\section{Origens da EC n. 29 de $\mathbf{2 0 0 0}$}

A Constituição da República de 1988 (CR/88) definiu que as ações e serviços públicos de saúde "integram uma rede regionalizada e hierarquizada e constituem um sistema único", o SUS, organizado segundo as diretrizes da descentrali- 
zação, com mando único em cada esfera de governo, atendimento integral e participação da comunidade. A CR/88 definiu também que o SUS seria financiado pelos Orçamentos da Seguridade Social (OSS) da União, dos estados e dos municípios. Ainda que a CR/88 tenha estabelecido que as três esferas de governo devam participar de seu financiamento, essa determinação foi feita de forma imprecisa, não tendo sido estabelecidos critérios para tanto (Santos, 1994; Médici, 1994; Vianna, 2000).

Ao longo da década de 1990, o SUS enfrentou sérios problemas de financiamento em decorrência das repercussões negativas da política de ajuste fiscal sobre o OSS e do tratamento prioritário concedido à previdência no seu interior (Ugá e Marques, 2005). O SUS ressentiu-se ainda do pouco comprometimento das esferas subnacionais - em particular, dos estados - para com o seu financiamento. Nesse último caso, as regras da descentralização da política de saúde e as 170 condições restritivas impostas pela crise fiscal e pelos esforços da União para enfrentá-la contribuíram para o relativo afastamento da esfera estadual e para a redução de sua participação no total do gasto público com saúde.

A partir das determinações contidas na CR/88 e nas Leis Orgânicas da Saúde (LOS), as regras de implementação do SUS têm sido definidas, principalmente, por meio de normas operacionais (NOBs). Se essas normas mostraram-se capazes de estimular a adesão dos governos municipais ao SUS, o mesmo não se pode dizer com relação aos estados. Isto porque os incentivos previstos - recursos financeiros para a oferta de serviços -, eficientes em promover a descentralização de corte municipalizante e em aumentar o comprometimento dos municípios com os gastos em saúde, não alcançaram os estados. Além de não terem sido contemplados com incentivos financeiros, que se destinavam, basicamente, ao pagamento de serviços prestados, em princípio, pelo nível municipal, e de não 
terem seu papel bem especificado pelas regras da descentralização, os estados também não se beneficiaram, como os municípios, da descentralização fiscal promovida pela $\mathrm{CR} / 88^{1}$. A capacidade de gasto de muitos estados encontrava-se reduzida, ainda, em decorrência do endividamento e do intenso processo de reestruturação financeira, o que os levou a comprometer parcela importante de suas receitas com o pagamento de suas dívidas internas.

Diante desse quadro, a constitucionalização de responsabilidades relativas ao financiamento do SUS por parte das três esferas de governo passou a ser considerada a estratégia mais apropriada, defendida por ampla coalizão de atores, para reverter uma situação caracterizada pela instabilidade dos recursos e pela presença de "caronas" (Olson, 1965). Como consequência, começaram a surgir, no âmbito do Congresso Nacional, Propostas de Emendas Constitucionais (PECs) que vinculavam recursos para a saúde.

A primeira proposta de emenda constitucional, de autoria dos deputados Eduardo Jorge e Waldir Pires (ambos do PT), surgiu em 1993: a PEC 169. Entre 1993 e 1998, diversas propostas de vinculação de recursos orçamentários dos três níveis de governo para a saúde foram elaboradas e discutidas no Congresso Nacional, enfrentando sempre a resistência da área econômica do governo². A partir de 1998, a discussão da vinculação de recursos foi acelerada no Congresso, após obter apoio explícito do presidente da República. Essa mudança de estratégia não significou intenção do governo federal em aumentar sua participação no financiamento do SUS, haja vista as inúmeras ações em sentido

\footnotetext{
1 No processo de redistribuição dos recursos públicos ocorrido nas décadas de 1980 e de 1990, em termos verticais, quase todos os ganhos relativos couberam à esfera municipal, pouco se alterando a posição do nível estadual, sobretudo no conceito de receita tributária disponível (arrecadação própria e transferências constitucionais) (Serra e Afonso, 1999).

2 Para uma análise detalhada sobre as diferentes PECs, consultar Mendes e Marques (1999) e Piola et al. (2000).
} 
contrário, tais como a aprovação do Fundo de Estabilização Fiscal (FEF) ${ }^{3}$ e o desvio de recursos da Contribuição Provisória sobre Movimentação Financeira (CPMF).

Dois propósitos motivaram essa conduta do governo federal: forçar o aumento da participação das esferas subnacionais, em particular dos estados, e desvincular os recursos da CPMF da saúde, para o que seria necessário indicar uma nova fonte de custeio para o setor (Menicucci, 2003). Vale lembrar que os esforços para agilizar a tramitação da PEC coincidiam com a aproximação do término de vigência da CPMF, previsto para 31 de dezembro de 1999.

A partir de um acordo suprapartidário, foi possível aprovar, em tramitação acelerada, sob a forma de uma emenda aglutinativa, a PEC n. 82/1995, do deputado Carlos Mosconi, do partido governista, resultado da fusão de várias PECs (entre as quais a PEC 169). Diferentemente da PEC 169 original, o governo federal acabou isento da vinculação 172 de percentual da receita. A falta de consenso e a pressão da área econômica remeteram para a lei complementar, prevista na EC n. 29, a definição das receitas federais sobre as quais incidiria a vinculação para a saúde. De todo modo, ao definir a participação das três esferas de governo, a EC n. 29 constitui a iniciativa mais abrangente de regularização do financiamento do SUS.

A aprovação da EC n. 29 não acabou com as divergências entre ministros e com a forte resistência de governadores. Tratou-se, antes, de um consenso provisório. No momento de implementar o que havia sido acordado, os conflitos de interesses, que se fizeram presentes ao longo do período de tramitação, logo retornaram à cena.

\footnotetext{
${ }^{3}$ O FEF (EC n. 10/1996), que substituiu o Fundo Social de Emergência (FSE), permitia que $20 \%$ das receitas de impostos e contribuições arrecadados pela União pudessem ser alocados livremente, reduzindo, dessa forma, o montante de recursos que o governo federal deveria repassar aos estados e aos municípios.
} 


\section{0 longo processo de regulamentação da EC n. 29 de $2000^{4}$}

O processo de regulamentação da EC n. 29 teve início na Câmara dos Deputados, em fevereiro de 2003, com a apresentação do Projeto de Lei Complementar (PLP) 01/2003, do deputado Roberto Gouveia (PT-SP). Ao longo desse processo, a EC n. 29 passou a estimular disputas relacionadas ao conceito de "ações e serviços de saúde" e à base de cálculo para a definição da participação da União a partir de 2001. Essas duas questões constituem os principais questionamentos que a EC n. 29 suscitou. Com relação ao primeiro, a EC n. 29, de fato, não apresenta uma definição do que pode ser computado como gasto com saúde, favorecendo o conflito entre os que defendem um conceito mais restrito e aqueles que advogam a favor de uma definição mais abrangente.

O segundo questionamento gera o famoso embate "base fixa" versus "base móvel" entre o Ministério da Saúde e o Ministério da Fazenda. Para o ano de 2000, a EC n. 29 definiu que o valor do gasto da União deveria ser igual ao "montante empenhado em ações e serviços públicos de saúde no exercício financeiro de 1999 acrescido de, no mínimo, cinco por cento". Os problemas surgem, entretanto, para os anos de 2001 a 2004, à medida que a EC n. 29 estabelece que os recursos mínimos a serem aplicados deveriam ser equivalentes ao "valor apurado no ano anterior, corrigido pela variação nominal do Produto Interno Bruto”.

À medida que as negociações para a regulamentação da EC n. 29 se arrastavam, ela sofreu vetos dos níveis federal e estadual por meio da adoção de artifícios com o objetivo de fazer crer que ela estava sendo cumprida. Além da inclusão no cálculo do gasto com saúde, para efeitos de cumprimento da EC n. 29, de despesas que se mostravam em

\footnotetext{
4 A regulamentação da EC n. 29 foi aprovada no Senado em 7 de novembro 2011, quando este artigo já havia sido submetido ao conselho editorial desta revista.
} 
claro desacordo com o que determina a Portaria n. 2047 do $\mathrm{MS}^{5}$, os governos estaduais apresentaram graus diferentes de compromisso com o Sistema de Informações sobre Orçamentos Públicos sobre Saúde (Siops).

Tal sistema, que começou a ser implantado pelo Executivo federal em 1999 com os objetivos de coletar, armazenar, processar e divulgar dados relativos às receitas e às despesas com saúde dos três níveis de governo, tem a responsabilidade de acompanhar a implementação da EC n. 29. As informações disponíveis dão conta de que, em 2003, apenas os estados de São Paulo, Rondônia, Mato Grosso e Tocantins haviam preenchido o Siops (Marques e Mendes, 2005). Em junho de 2006, seis estados ainda não haviam informado os dados referentes a 2004, a saber: Paraíba, Espírito Santo, São Paulo, Rio Grande do Sul e Paraná. O caso do Rio Grande do Sul pode ser considerado o mais grave, já que naquela data só havia disponibilizado os 174 dados de 2002 (Fortes, 2008).

\section{Contexto das escolhas dos governadores - as variáveis selecionadas}

Argumenta-se aqui que as escolhas dos governadores relativas aos gastos com saúde são constrangidas pela EC n. 29 e, também, por decisões prévias, por fatores de natureza política e pelas condições estruturais dos estados.

\section{0 efeito do ponto de partida}

Entre as variáveis das escolhas dos governadores, há que se considerar decisões passadas e incorporar na análise a

\footnotetext{
${ }^{5}$ Essa portaria, que dispõe sobre as diretrizes operacionais para a aplicação da EC n. 29, teve por base resolução do Conselho Nacional de Saúde, que, por sua vez, resultou de discussões envolvendo as três esferas de governo. Dessas discussões, resultou, já no primeiro semestre de 2001, o documento "Parâmetros consensuais sobre a implementação e regulamentação da EC n. 29", que, entre outros pontos, buscou esclarecer a questão do "ano anterior" e estabeleceu um conceito de ações e serviços de saúde.
} 
ideia de "dependência de trajetória", enfatizada pelo novo institucionalismo histórico (Hall e Taylor, 1996; Pierson, 1995). Nesse sentido, a influência das escolhas prévias expressa no percentual da receita aplicado em ações e serviços de saúde antes da EC n. 29 será investigada como um fator capaz de condicionar o comportamento dos governadores no período posterior à EC n. 29.

Sabe-se que a distribuição dos recursos orçamentários entre os diversos setores, uma vez feita, fortalece determinados atores, incentiva alianças e cria capacidade técnica e administrativa. Nesse sentido, promover alterações significativas na alocação de recursos não é uma questão trivial. Além de demandar o enfrentamento de interesses constituídos, expressos em certo padrão de despesa pública, aumentar os gastos num dado setor requer capacidade institucional das burocracias. Com base nesse pressuposto, argumenta-se que, quanto mais baixos os percentuais aplicados antes da EC n. 29, maior o esforço exigido das unidades federativas e maiores as dificuldades para cumpri-la. Para os estados que já gastavam, antes da EC n. 29, mais de $12 \%$ de suas receitas com saúde ela não traria constrangimentos adicionais.

\section{O efeito das variáveis políticas}

Entre as variáveis políticas, a influência dos partidos nas decisões governamentais é recorrente objeto de investigação da literatura política, desde, pelo menos, a década de $1950^{6}$. Nesses estudos, as diferenças na orientação ideológica dos partidos são testadas como o principal fator explicativo para a escolha de diferentes políticas (Ribeiro, 2006). Para essa discussão, a contribuição de Downs (apud Blais et $a l ., 1993$, p. 41) forneceu um importante ponto de partida. Segundo esse autor, as posições ideológicas podem ser

\footnotetext{
${ }^{6}$ Para uma revisão sucinta da literatura a esse respeito, consultar Ribeiro (2006).
} 
ordenadas numa escala que vai da esquerda à direita de acordo com o grau desejado de intervenção do estado na economia, considerada a principal diferença entre elas.

Ainda que os resultados dos diversos estudos consultados (Arretche e Marques, 2002; Blais et al., 1993; Dias, 1997; Rodrigues, 2003; Ribeiro, 2006) indiquem que as escolhas alocativas dos gestores não guardam relação significativa com as siglas partidárias, o perfil ideológico do governador, medido por sua filiação partidária, será testado como uma variável que pode influenciar as decisões alocativas dos governos estaduais. Objetiva-se, dessa forma, contribuir com mais uma evidência para esse debate. Para tanto, os partidos foram agrupados, de acordo com Melo (2000) ${ }^{7}$, em: direita, centro e esquerda. O perfil de esquerda será tomado como referência, ou seja, será testado se os partidos de centro e de direita diferenciam-se dos de esquerda.

\section{Os efeitos da condição estrutural dos estados}

A discussão teórica sobre os determinantes das políticas sociais aponta para a importância de considerar o contexto socioeconômico como um fator capaz de criar uma estrutura de oportunidades e/ou de restrições para as escolhas políticas (Ribeiro, 2006). Em que pese tal fato, os inúmeros estudos empíricos sobre os determinantes dos gastos com saúde apresentam resultados insatisfatórios e têm gerado mais perguntas que respostas (Gerdtham e Jönsson, 2000).

À luz do que foi colocado, decidiu-se testar se diferenças econômicas, fiscais, sociais e demográficas entre os estados estariam influenciando as respostas dos governadores à EC n. 29. Para tanto, as seguintes variáveis foram selecionadas: a) capacidade de gasto; b) desempenho das bases econômica e tributária; c) comprometimento da receita com os

\footnotetext{
${ }^{7}$ Partidos de esquerda: PT, PDT, PSB, PC do B, PPS e PV; como de centro: PMDB e PSDB; e como de direita: PFL, PPB, PTB e PL. As pequenas legendas também foram consideradas e agrupadas segundo o mesmo critério.
} 
gastos com pessoal; d) percentual da população com mais de 65 anos; e) percentual da população com menos de 1 ano; f) percentual da população entre 1 e 4 anos; g) percentual da população urbana.

A capacidade de gasto, medida pela receita líquida per capita $^{8}$, permite comparar os estados em termos da disponibilidade de recursos por habitante de que dispõe o governador para fazer face às despesas. A escolha desse indicador apoia-se no argumento de que a disponibilidade de recursos afeta as capacidades decisória, financeira e administrativa dos estados (Arretche, 2000; Souza, 2005). ${ }^{9}$ O pressuposto é o de que maior disponibilidade de recursos confere maior poder de manobra ao gestor para propor alterações no orçamento.

Os dados relativos à receita líquida foram coletados no Siops, do Ministério da Saúde ${ }^{10}$. Os valores foram atualizados pelo Índice Geral de Preços/ Disponibilidade Interna (IGP-DI), da Fundação Getúlio Vargas, e são apresentados a preços médios de 2004. Os valores per capita de cada ano foram obtidos a partir da divisão da receita líquida total de cada estado pela respectiva população, segundo o Instituto Brasileiro de Geografia e Estatística (IBGE).

\footnotetext{
8 Também denominada "receita vinculada", é composta pelos impostos estaduais e pelas transferências constitucionais recebidas da União deduzida a parcela transferida aos municípios. Os impostos estaduais são os seguintes: Imposto sobre Operações Relativas à Circulação de Mercadorias e Prestação de Serviços de Transporte Interestadual e de Comunicação (ICMS), Imposto sobre a Propriedade de Veículos Automotores (IPVA), Imposto sobre Transmissão "Causa Mortis" e Doação de Bens e Direitos (ITCMD). As receitas de transferências são as seguintes: Fundo de Participação dos Estados e do DF (FPE), Imposto de Renda Retido na Fonte (IRRF), Imposto sobre Produtos Industrializados (IPI Exportação) e Lei Kandir (Lei Complementar n. 87/96).

9 Analisando os determinantes da descentralização das políticas sociais, Arretche (2000) concluiu que atributos estruturais como a capacidade fiscal, dentre outros, constituem variáveis capazes de interferir nas decisões dos gestores municipais, ainda que não sejam determinantes em si.

${ }^{10}$ Dados disponíveis na página eletrônica http://portalsaude.saude.gov.br/portalsaude/area/400/siops.html.
} 
O desempenho das bases econômica e tributária dos estados será aferido por meio do indicador de desempenho tributário e econômico (IDTE). A partir da relação entre as receitas tributárias dos estados - oriundas, portanto, de sua base produtiva - e as receitas provenientes das transferências do Fundo de Participação dos Estados (FPE) - que não guardam relação com a base econômica - esse indicador permite extrair conclusões sobre o estágio de desenvolvimento econômico e tributário dos estados (Fundação João Pinheiro, 1998) ${ }^{11}$. Os dados referentes à receita tributária e ao FPE foram extraídos da Execução Orçamentária dos Estados (1995-2006) ${ }^{12}$.

É interessante perceber que esse indicador complementa as informações fornecidas pelo anterior (capacidade de gasto), ou seja, enquanto este caracteriza os estados em termos da disponibilidade de recursos por habitante, aquele permite inferências sobre a potencialidade de arrecadação da base econômica. Vale lembrar que a capacidade de gas178 to dos estados, dadas as regras do federalismo fiscal brasileiro, não reflete, necessariamente, o potencial econômico e tributário deles. A respeito da influência desse indicador nas escolhas dos governadores estaduais, argumenta-se que o nível de desenvolvimento econômico e tributário é uma variável que tem repercussões no potencial de arrecadação dos governos e, consequentemente, pode conferir maior/ menor poder de decisão aos governantes (Arretche, 2000).

O comprometimento da receita com os gastos com pessoal será medido pela participação das despesas com pessoal na receita corrente líquida. Esta foi calculada de acordo com a

\footnotetext{
${ }^{11}$ IDTE $=$ receita tributária/transferência do FPE. IDTE $<1:$ O estado classifica-se entre os de baixo desempenho econômico e tributário, já que sua receita deriva, predominantemente, das transferências do FPE, que não são determinadas por sua base econômica. IDTE > 1: O estado classifica-se entre os de maior desempenho econômico e tributário, cujo grau aumenta diretamente com a elevação do IDTE.

${ }^{12}$ Dados disponíveis na página eletrônica da Secretaria do Tesouro Nacional (STN) do Ministério da Fazenda http://www.tesouro.fazenda.gov.br.
} 
definição da Lei de Responsabilidade Fiscal (LRF), ou seja, trata-se da receita corrente total dos estados, deduzidas as transferências constitucionais aos municípios. Os dados relativos à receita e à despesa com pessoal também foram extraídos da Execução Orçamentária dos Estados (entre 1995 e 2006) disponível na página eletrônica da STN. A escolha dessa variável justifica-se porque a LRF estabelece limites máximos para os gastos com pessoal ativo e inativo, o que restringe a autonomia dos entes governamentais para contratar funcionários. Ainda que se reconheça que pode haver crescimento dos gastos com saúde sem que se tenha, necessariamente, de aumentar os gastos com pessoal, argumenta-se que um elevado comprometimento da receita com pessoal pode dificultar, num curto período de tempo, a elevação das despesas com saúde.

O efeito da estrutura etária da população será testado em sintonia com os estudos que buscam detectar os determinantes do comportamento dos gastos com saúde na literatura internacional. O argumento é o de que a maior participação de pessoas com mais de 65 anos, com menos de 1 ano e com idade entre 1 e 4 anos na população total favorece o aumento dos gastos com saúde.

Por fim, será testado se a taxa de urbanização tem influência sobre a trajetória dos gastos. A hipótese é a de que maiores taxas estariam associadas a maiores gastos.

\section{A EC n. 29 de 2000 e os gastos dos governos estaduais e do DF com assistência à saúde}

Esta seção está dividida em duas partes. A primeira apresenta uma análise descritiva dos períodos 1998-2000 (antes da EC n. 29) ${ }^{13}$ e 2001-2004 (após a EC n. 29). A segunda testa a influência de variáveis de contexto nas escolhas dos governadores.

\footnotetext{
${ }^{13}$ Como a Emenda foi promulgada no final de 2000, acordou-se sua vigência a partir do ano de 2001 em função da dificuldade em providenciar suplementações substanciais nos orçamentos. Com base nisso, considerou-se que ela passou a afetar o comportamento dos entes federativos, de fato, a partir de 2001.
} 
Ainda que os dados utilizados neste estudo tenham como fonte o Siops, as informações relativas aos anos de 1998 e 1999 foram obtidas com Ana Cecília Faveret, que participou do processo de estruturação do sistema e utilizou esses dados em sua tese de doutorado (Faveret, 2002). Embora façam parte da base de dados do Siops, eles já não estão disponíveis em sua página eletrônica. Os dados relativos ao período de 2000 a 2004 foram extraídos das Notas Técnicas do Siops ${ }^{14}$. Tais dados que, assim como aqueles referentes à 1998 e 1999, passaram por um processo de conferência realizado pela equipe do Siops, apresentam divergências quando comparados com os declarados pelos gestores, os quais também estão disponíveis nona referida página eletrônica. As diferenças dizem respeito aos valores dos gastos, à receita líquida e, consequentemente, aos percentuais aplicados.

180 Gastos com saúde dos governos estaduais no período 1998-2004 15

Entre 1998 e 2000 - e, portanto, antes da EC n. 29 -, a variação dos percentuais da receita líquida aplicados pelos estados e pelo Distrito Federal na saúde oscilou de um aumento de $125 \%$, no Amapá, a uma redução de 69,60\%, no Mara-

\footnotetext{
${ }^{14}$ Tomando por base as definições estabelecidas pela Resolução 322 do Conselho Nacional de Saúde, equipe do Siops analisa e compara os dados relativos às despesas em ações e serviços públicos de saúde e à receita líquida apresentados pelos estados e pelo distrito federal nos balanços gerais, nos relatórios resumidos de execução orçamentária e ao Siops. Disponível em http://portalsaude.saude.gov. br/portalsaude/area/400/siops.html. Notas técnicas n. 010/2004, n. 009/2005 e n. $49 / 2006$.

${ }^{15}$ A definição do período de análise - 1998 a 2004 - justifica-se, no caso do último ano, pelo fato de ser esse o estipulado pela EC n.29 para os estados atingirem o percentual de $12 \%$ de suas receitas comprometido com as ações e os serviços de saúde. Além disso, quando da coleta dos dados, aqueles relativos aos anos mais recentes ou não haviam sido informados por todos os estados ou não tinham passado por um processo de consistência por parte do Siops. Já o ano de 1998 é o primeiro com dados sistematizados para todos os estados que seguiram um padrão de coleta e de consistência (Faveret, 2000).
} 
nhão (Tabela 1) ${ }^{16}$. A maioria dos estados (dezenove), entretanto, diminuiu a participação dos gastos com saúde na receita líquida.

Em 2000, ano em que a EC n. 29 foi promulgada, os gastos com saúde como proporção da receita líquida dos governos estaduais oscilavam entre 1,52\%, no Maranhão, a $19,11 \%$, no Acre (Tabela 1). Onze estados aplicavam menos de 7\%, mínimo estipulado pela EC n. 29 como ponto de partida. Por outro lado, em quatro estados esse percentual era superior a 12\%, mínimo a ser atingido por todos até 2004 (Acre, Amazonas, Amapá e Rio Grande do Norte).

Com pontos de partida tão diferenciados, percebe-se que a EC n. 29 impôs aos estados um esforço bastante desigual para cumpri-la.

Tomando-se, agora, o período 2001-2004, constata-se que o comportamento dos estados também variou significativamente, apresentando desde uma elevação de $307 \%$, no Maranhão, a um decréscimo de 42\%, na Paraíba (Tabela 2). No entanto, diferentemente do que se observou antes da EC n. 29, a maioria dos estados elevou o gasto com saúde como proporção da receita líquida. Vale ressaltar que esse aumento foi acompanhado de uma redução na diferença entre eles nesse aspecto, haja vista que o coeficiente de variação ${ }^{17}$ diminuiu entre 2000 e 2004 (tabelas 1 e 2).

No que se refere ao cumprimento da EC n. 29, em que pesem os aumentos dos percentuais da receita aplicados na saúde, ele não se deu na maioria dos estados entre 2001 e 2004 (Tabela 2). Em 2004, quando todos os estados deveriam atingir o mínimo de $12 \%$, apenas sete o fizeram: Amazonas, Amapá, Distrito Federal, Acre, Rio Grande do Norte, Ceará e Roraima. Cinco estados atingiram percentu-

\footnotetext{
${ }^{16}$ As tabelas 1, 2 e 3 estão apresentadas no Anexo, ao final deste artigo.

${ }^{17} \mathrm{O}$ coeficiente de variação constitui uma maneira de se expressar a variabilidade dos dados tirando a influência da ordem de grandeza da variável. Coeficiente de variação $=$ desvio padrão/média.
} 
ais muito próximos do mínimo estipulado: Tocantins, Piauí, Pernambuco, Bahia e Santa Catarina. Por outro lado, Rio Grande do Sul (RS) e Mato Grosso do Sul apresentaram percentuais muito baixos relativamente aos demais $-5,43 \%$ e $6,15 \%$, respectivamente.

Para o desempenho apresentado pelo RS, pode-se supor, contribuíram as sérias dificuldades fiscais deste estado. A análise dos relatórios de responsabilidade fiscal de sete ${ }^{18}$ estados brasileiros entre 1998 e 2002, feita por Lopreato (2004), mostrou que se a questão do endividamento era preocupante em todos eles, o Rio Grande do Sul se destacava como o único que não conseguiu contribuir para o superávit primário global em 2001 e 2002, ou seja, suas receitas não se mostraram suficientes nem para fazer face às despesas não financeiras.

Entre os estados que conseguiram atingir o percentual de $12 \%$ em 2004, todos já comprometiam mais de $7 \%$ de 182 suas receitas líquidas com a saúde em 2000, mínimo estipulado para aquele ano (tabelas 1 e 2). Os estados que aplicavam na saúde percentual inferior a $7 \%$ não conseguiram, no espaço de tempo estipulado, reverter essa situação de modo a cumprir a EC n. 29.

Merece registro ainda o fato de a trajetória dos estados no período 2001-2004 ter variado tanto entre eles como num mesmo estado ao longo do tempo. Ou seja, o aumento dos percentuais não foi gradativo, como estipulou a EC n. 29. De fato, na grande maioria dos estados o percentual aplicado em cada ano ficou aquém do estabelecido. Além disso, poucos estados apresentaram uma trajetória de crescimento contínuo.

Considerando-se agora os valores do gasto per capita, observa-se que entre 2001 e 2004 a grande maioria dos estados (21) elevou o valor do mesmo. Esse aumento, no

\footnotetext{
${ }^{18}$ São Paulo, Rio de Janeiro, Minas Gerais, Rio Grande do Sul, Ceará, Bahia e Goiás.
} 
entanto, mostrou-se bastante diferenciado, tendo variado de 1,5\%, no Espírito Santo, a 274\%, no Maranhão (Tabela 3). Esse comportamento refletiu, basicamente, o maior comprometimento da receita com saúde e, pode-se supor, a influência da EC n. 29, à medida que a receita líquida per capita só cresceu em cinco estados e, assim mesmo, com exceção de Rondônia, em percentuais inferiores à elevação observada nos gastos (Fortes, 2008). Comparando o gasto per capita dos estados em 2004, observa-se que seu valor apresentava uma variação significativa, oscilando entre cerca de R\$34, no Maranhão, e R \$281, no Amapá (Tabela 3).

A respeito das diferenças nos valores dos gastos per capita cabem, pelo menos, quatro observações. Em primeiro lugar, embora o valor do gasto, isoladamente, seja insuficiente para permitir inferências a respeito da condução da política de saúde, conforme argumenta Arretche (2000), pode-se supor que a desigualdade de recursos financeiros favoreça a desigualdade no acesso a serviços de saúde, que se constitui, por sua vez, em um dos determinantes das desigualdades nesse setor (Whitehead, 1991) ${ }^{19}$.

Em segundo lugar, à medida que o valor do gasto com saúde depende não apenas do percentual da receita comprometida com saúde, mas também de seu montante, a redução na disparidade dos valores encontrados requer o enfrentamento das distorções do federalismo fiscal brasileiro, distorções que favorecem as enormes diferenças em termos da receita líquida per capita (Rezende e Afonso, 2004).

\footnotetext{
${ }^{19}$ De acordo com Whitehead (1991), são sete os determinantes de desigualdades em saúde: (a) variação natural, biológica; (b) comportamento insalubre livremente escolhido; (c) vantagens transitórias resultantes da adoção gradual de novos recursos de promoção da saúde; (d) comportamentos danosos compulsórios; (e) exposição a condições deletérias de trabalho e vida; (f) acesso inadequado a serviços; (g) seleção natural que leve a mobilidade social descendente.
} 
A terceira observação visa enfatizar que a discussão sobre as desigualdades dos valores do gasto per capita deve considerar a despesa realizada pelas três esferas de governo. Como as regras do federalismo fiscal não têm sido eficazes para reduzir as enormes disparidades na receita entre municípios, estados e regiões, é fundamental que as transferências federais do SUS sejam pautadas por critérios que busquem, entre outros aspectos, compensar essas desigualdades. Daí a importância de regras que visem garantir não apenas patamares mínimos de comprometimento da receita com a assistência à saúde, mas também que cidadãos, em diferentes partes do país, tenham acesso ao mesmo nível de tratamento para necessidades iguais.

Como última observação, tem-se que as diferenças acentuadas estimulam ainda a discussão sobre a qualidade do gasto, ou seja, sobre o seu impacto na atuação 184 da esfera estadual e, em última instância, na oferta de serviços para a população; afinal, isso é que realmente importa. Essas questões sugerem uma nova agenda de pesquisa, na qual se buscaria investigar que atividades foram favorecidas pelo aumento do gasto com saúde provocado pela EC n. 29.

\section{Efeitos da EC n. 29 e de fatores contextuais sobre os percentuais da receita líquida aplicados na saúde pelos estados e pelo DF}

Nessa seção será testado se, além da EC n. 29, variáveis de contexto - políticas e que descrevem características estruturais dos estados - explicam parcelas significativas da variação encontrada nas respostas dos governadores à EC n. 29.

Os dados utilizados estão organizados em uma planilha com 189 linhas, cada uma correspondente a uma das 27 unidades da federação e a um dos 7 anos (1998 a 2004), e contém o valor de cada uma das seguintes variáveis: 
a) percentual da receita líquida aplicado na saúde pelos estados e pelo DF no período de 1998 a 2004 ( \% aplic) ${ }^{20}$ - variável dependente;

As demais são as covariáveis, isto é, variáveis cujo potencial explicativo será analisado.

b) variável indicadora ${ }^{21}$ (emenda) que assume o valor 0 para os anos de 1998, 1999 e 2000 e o valor 1 para os anos de 2001, 2002, 2003 e 2004;

c) variáveis indicadoras para o perfil ideológico do partido do governador. Como se trata de uma variável com três categorias (direita, centro e esquerda), para sua inclusão no modelo de análise foi necessário transformá-la em duas variáveis indicadoras: perfil 1 e perfil 2. A variável perfil 1 capta o efeito no percentual da receita aplicado na saúde quando se passa de um estado com governador de partido de esquerda - tomado como referência - para um estado com governador de partido de centro. A variável perfil 2 capta o efeito no percentual da receita aplicado na saúde quando se passa de um estado com governador de partido de esquerda para um estado com governador de partido de direita;

d) receita líquida per capita ( rec liq per). Essa variável e as seguintes expressam características estruturais dos estados que, conforme argumentado, permitem diferenciá-los nos aspectos econômicos, fiscais e sociais e, assim, caracterizar os distintos contextos de implementação da EC n. 29. Cada estado foi descrito em cada variável, pela mediana do período.

e) participação dos gastos com pessoal na receita corrente líquida (pes $r c l$ );

f) potencial da base econômica e tributária (idte);

\footnotetext{
${ }^{20} \mathrm{Na}$ realidade, usou-se o logito do percentual, como é usual na literatura estatística para análises em que a variável dependente é um percentual ou uma probabilidade (Hosmer e Lemeshow, 2000). Dado o percentual p, o logito de $\mathrm{p}=$ $\log$ p/1-p. Essa transformação "não afeta em nada a interpretação substantiva dos parâmetros" (Castro, 1993, p. 489).

${ }^{21}$ Quando se tem uma diferença como categoria explicativa utiliza-se uma variável indicadora, ou dummy, para captá-la.
} 
g) percentual da população com mais de 65 anos ( $p o p-65$ anos);

h) percentual da população com menos de 1 ano ( $p o p-1$ ano);

i) percentual da população entre 1 e 4 anos ( pop - 1 a 4 anos);

j) percentual da população urbana (popurbana).

Trata-se, portanto, de um conjunto de dados nos quais os estados da federação e o DF são acompanhados ao longo do tempo. Assim, todas as variáveis, nos diferentes anos, para um mesmo estado e o DF, não fornecem informações independentes, já que dizem respeito às mesmas unidades da federação, em períodos de tempo subsequentes. Nessas condições, o uso da regressão linear simples é inadequado, sendo necessária a adoção de técnica mais apropriada.

Como alternativa, utilizou-se como ferramenta de análise os modelos lineares hierárquicos (ou multiníveis) de regressão múltipla ${ }^{22}$. O modelo ajustado assume que 186 o comportamento da variável dependente é função de variáveis explicativas de dois níveis. Aquelas cujo nível de observação diz respeito aos anos da medida estão no nível 1, ou seja, para cada ano existe uma medida de cada variável (existência ou não da EG n. 29 e perfil do partido do governador). No nível 2, estão as variáveis que representam as características estruturais dos estados. Vale lembrar que para cada variável foi tomada a mediana do período.

Numa etapa inicial da análise, foi ajustado um modelo com todas as covariáveis. Como, além da EC n. 29, apenas as covariáveis receita líquida per capita, perfil 1 e perfil 2 mostraram-se significativas, decidiu-se pelo modelo de dois níveis, expresso nas equações [1], [2], [3], [4] e [5] abaixo.

\footnotetext{
${ }^{22}$ Para mais informação sobre essa técnica estatística, consultar Raudenbush e Bryk (2002).
} 
Nível 1:

$\%$ aplic $\mathrm{ti}=\mathrm{Boi}+\mathrm{B} 1 \mathrm{i}^{*}$ emendat $\mathrm{i}+\mathrm{B} 2 \mathrm{i}^{*}$ perfil $1 \mathrm{ti}+\mathrm{B} 3 \mathrm{i}^{*}$ perfil $2 \mathrm{ti}+\mathrm{Rti}[1]$

Onde t representa o tempo e i o estado.

- emendati $=0$ se $\mathrm{t}<=3$ e 1 se $\mathrm{t}>$ ou $=4$ e

- perfil 1ti = Diferença do governador de partido de centro em relação ao de partido de esquerda.

- perfil 2ti = Diferença do governador de partido de direita em relação ao de partido de esquerda.

Os coeficientes da equação [1] representam:

Boi $=$ valor médio do percentual da receita aplicado na saúde pelos estados antes da EC n. 29;

B1i = efeito da covariável emenda sobre o percentual da receita aplicado na saúde em cada um dos estados;

$\mathrm{B} 2 \mathrm{i}$ = efeito da covariável perfil ideológico do partido do governador sobre o percentual da receita aplicado na saúde. Indica a diferença dos partidos de centro relativamente aos de esquerda;

B3i = o mesmo que o anterior, só que, nesse caso, indica a diferença dos partidos de direita relativamente aos de esquerda;

Rti = capta a influência de outros fatores que explicam o percentual da receita aplicado na saúde, mas que não foram medidos.

Nível 2:

Boi $=\mathrm{G} 00+\mathrm{G} 01 *$ rec liq peri $+\mathrm{U} 0 \mathrm{i}[2]$

$\mathrm{B} 1 \mathrm{i}=\mathrm{G} 30+\mathrm{G} 31 *$ rec liq peri $+\mathrm{U} 1 \mathrm{i}[3]$

$\mathrm{B} 2 \mathrm{i}=\mathrm{G} 10[4]$

$\mathrm{B} 3 \mathrm{i}=\mathrm{G} 20[5]$

A equação [2] assume que o valor do percentual da receita aplicado na saúde por cada estado antes da EC n. 29 
(B0oi) tem um componente comum a todos eles (G00), associado ao fato de serem membros da Federação; outro componente associado ao seu nível de receita líquida per capita e, finalmente, um resíduo aleatório (U0i), que capta a especificidade de cada estado.

A equação [3] assume que o efeito da EC n. 29 varia entre os estados da Federação. Parte dessa variação está associada ao nível de sua receita líquida per capita e outra parte, representada pelo termo residual U1i que capta as outras diferenças entre os estados no que diz respeito à EC n. 29 que não aquela relativa às receitas.

O modelo assume, ademais, que há interação entre o efeito da EC n. 29 e a receita líquida per capita. Conforme mostra a equação [3], não existe mais um coeficiente único da EC n. 29 para todos os estados, mas um coeficiente (B1i $=\mathrm{G} 30+\mathrm{G} 31^{*}$ rec liq peri $\left.+\mathrm{U} 1 \mathrm{i}\right)$ que possui um componente comum a todos (G30) e um outro especificado pela 188 receita do estado (G31* rec liq peri). Em outras palavras, o modelo assume que o contexto de implementação da EC n. 29, no que se refere ao nível de receita líquida per capita, influencia o efeito desta.

As equações [4] e [5] assumem que o efeito do perfil ideológico do partido do governador sobre o percentual da receita aplicado na saúde não varia entre os estados, ou seja, que não há diferenças entre os subsistemas partidários estaduais. Este é um pressuposto forte que, sabe-se, restringe o alcance da análise, mas que foi necessário tendo em vista as limitações da ferramenta analítica adotada.

As estimativas dos coeficientes desse modelo, o desvio padrão e os resultados do teste t (significância) obtidas com o software HLM são apresentadas no Quadro 1. 


\section{Quadro 1:}

Resultados do modelo ajustado para o cálculo dos efeitos da Emenda 29 e das variáveis contextuais sobre o percentual da receita aplicado na saúde pelos estados e DF - Brasil - 1998-2004

\begin{tabular}{|c|c|c|c|}
\hline Efeitos fixos & Coeficiente (B) & Desvio padrão & Significância \\
\hline \multicolumn{4}{|l|}{ Para o intercepto, B0 } \\
\hline Intercepto, G00 & $-2,387995$ & 0,09164 & $0,000 * * *$ \\
\hline Rec liq per, G01 & 0,000514 & 0,000160 & $0,004^{* * *}$ \\
\hline \multicolumn{4}{|c|}{ Para a inclinação de Perfil 1, B2 } \\
\hline Intercepto, G10 & $-0,173930$ & 0,065646 & $0,008 * * *$ \\
\hline \multicolumn{4}{|c|}{ Para a inclinação de Perfil 2, B3 } \\
\hline Intercepto, G20 & $-0,254582$ & 0,109877 & 0,021 ** \\
\hline \multicolumn{4}{|c|}{ Para a inclinação de Emenda, B1 } \\
\hline Intercepto, G30 & 0,281805 & 0,068014 & $0,000 * * *$ \\
\hline Rec liq per, G31 & $-0,000233$ & 0,000113 & 0,050 ** \\
\hline
\end{tabular}

Os resultados dispostos no Quadro 2 mostram que a variável indicadora emenda para a aprovação da EC n. 29 contribui de modo altamente significativo para explicar o comportamento dos percentuais da receita aplicados na saúde. Para conhecer seu efeito, entretanto, é necessário informar o nível de receita líquida per capita do estado.

A variável rec liq per também se mostrou significativa. O sinal negativo de G31 indica que quanto maior a receita líquida per capita do estado, menor o efeito da EC n. 29 no percentual aplicado na saúde. No entanto, dado o baixo valor de seus coeficientes - G01 (0,50, depois da transformação) e de G31 (0,005, o mesmo) -, pode-se concluir que a receita líquida per capita está, do ponto 
vista substantivo, fracamente associada ao efeito da EC n. 29 sobre o percentual da receita aplicado na saúde pelos estados e pelo DF.

Com relação à variável perfil do partido do governador, pode-se dizer que, passando de um governo de esquerda para um de centro, o logito do percentual reduz em 0,17 ; ou, de modo equivalente, o percentual da receita aplicado na saúde reduz de $0,46 \%$. Quando se passa de um governo de esquerda para um de direita, o logito do percentual diminui em 0,25 , o que equivale a uma redução do percentual da receita aplicado de 0,44\%. Conclui-se que a variável em questão condiciona apenas marginalmente o percentual da receita aplicado na saúde, e que, portanto, a EC n.29 foi capaz de induzir as decisões dos governos estaduais independentemente da orientação dos partidos destes.

O teste do ajuste desse modelo foi feito usando-se 190 duas variáveis: "chipct" e "mdist" produzidas pelo próprio HLM para fins de verificação do ajuste do modelo (Raudenbush e Bryk, 2002) ${ }^{23}$. No caso de ajuste adequado, o gráfico dessas duas variáveis deve ser uma linha reta. Esse teste mostrou que dois estados, Rio Grande do Sul e Amazonas, não se enquadravam na síntese produzida pelo modelo. Isso já havia sido sugerido pela análise descritiva. Diante disso, ajustou-se um novo modelo no qual foram acrescentadas, entre as variáveis de primeiro nível, duas variáveis indicadoras relativas a esses dois estados, de modo a captar seus comportamentos singulares no tocante ao percentual da receita aplicado na saúde. Nos outros aspectos, esse modelo é igual ao anterior, conforme mostram as equações de [6] a [12].

\footnotetext{
${ }^{23}$ CHIPCT = distância entre os valores teóricos e os valores ajustados; MDIST = distância entre os valores observados e os valores ajustados.
} 
Nível 1:

$\%$ aplic $\mathrm{ti}=\mathrm{Boi}+\mathrm{B} 1 \mathrm{i}^{*}$ emendat $\mathrm{i}+\mathrm{B} 2 \mathrm{i}^{*}$ perfil $1 \mathrm{ti}+\mathrm{B} 3 \mathrm{i}^{*}$ perfil $2 \mathrm{ti}+$

B4i*Amazonas + B5i*Rio Grande do Sul + Rti [6]

Onde:

B4i = indica a mudança no logito do percentual da receita aplicado na saúde de modo a captar o comportamento singular do Amazonas.

B5i = indica a mudança no logito do percentual da receita aplicado na saúde de modo a captar o comportamento singular do Rio Grande do Sul.

As demais equações já foram explicadas na versão anterior do modelo sem as indicadoras para os estados do Amazonas e Rio Grande do Sul.

Nível 2:

Boi $=\mathrm{G} 00+\mathrm{G} 01 *$ rec liq peri $+\mathrm{U} 0 \mathrm{i}[7]$

$\mathrm{B} 1 \mathrm{i}=\mathrm{G} 30+\mathrm{G} 31 *$ rec liq peri $+\mathrm{U} 1 \mathrm{i}[8]$

$\mathrm{B} 2 \mathrm{i}=\mathrm{G} 10[9]$

$\mathrm{B} 3 \mathrm{i}=\mathrm{G} 20[10]$

$\mathrm{B} 4 \mathrm{i}=\mathrm{G} 40[11]$

$\mathrm{B} 5 \mathrm{i}=\mathrm{G} 50[12]$

As estimativas dos coeficientes desse modelo, o desvio padrão e os resultados do teste t (significância) obtidas com o software HLM são apresentadas no Quadro 2. 


\section{Quadro 2:}

Resultados do modelo ajustado para o cálculo dos efeitos da Emenda 29 e das variáveis contextuais sobre o percentual da receita aplicado na saúde pelos estados e DF - Brasil - 1998-2004

\begin{tabular}{|c|c|c|c|}
\hline Efeitos fixos & Coeficiente (B) & Desvio padrão & Significância \\
\hline \multicolumn{4}{|l|}{ Para o intercepto, B0 } \\
\hline Intercepto, G00 & $-2,499333$ & 0,092878 & $0,000 * * *$ \\
\hline Rec liq per, G01 & 0,691410 & 0,247676 & $0,010 * * *$ \\
\hline \multicolumn{4}{|c|}{ Para a inclinação de Perfil 1, B2 } \\
\hline Intercepto, G10 & $-0,131792$ & 0,062954 & $0,036^{* *}$ \\
\hline \multicolumn{4}{|c|}{ Para a inclinação de Perfil 2, B3 } \\
\hline Intercepto, G20 & $-0,237940$ & 0,116270 & 0,040 ** \\
\hline \multicolumn{4}{|c|}{ Para a inclinação de Emenda, B1 } \\
\hline Intercepto, G30 & 0,284239 & 0,068552 & $0,000 * * *$ \\
\hline Rec liq per, G31 & $-0,360872$ & 0,163319 & $0,036^{* *}$ \\
\hline $\begin{array}{l}\text { Para a inclinação de } \\
\text { Amazonas, B4 }\end{array}$ & 0,993070 & 0,071473 & 0,000 \\
\hline Intercepto, G40 & 0,993070 & 0,071473 & $0,000 * * *$ \\
\hline \multicolumn{4}{|c|}{ Para a inclinação de Rio Grande do Sul, B5 } \\
\hline Intercepto, G50 & $-0,548506$ & 0,053359 & $0,000 * * *$ \\
\hline
\end{tabular}

*** Significativo a $1 \%$; ** Significativo a $5 \%$.

As informações apresentadas no Quadro 2 mostram que os coeficientes, com exceção daqueles da receita líquida per capita, ficaram praticamente inalterados, e que, portanto, os resultados são os mesmos já apresentados. Apesar do coeficiente mais elevado, a receita líquida per capita continua fracamente associada ao efeito da EC n. 29 sobre o percentual da receita aplicado na saúde pelos estados e pelo DF. 
Cabe acrescentar apenas que as variáveis indicadoras para os estados (Amazonas e Rio Grande do Sul) mostraram-se altamente significativas. Corroborando o que já havia sido sugerido pela análise descritiva, o percentual aplicado pelo estado do Amazonas é maior (coeficiente positivo) do que seria esperado se o comportamento deste estado fosse semelhante ao dos outros estados. De modo análogo, o percentual aplicado pelo estado do Rio Grande do Sul é menor (coeficiente negativo) do que seria esperado se o comportamento deste estado fosse semelhante ao dos demais estados.

Por fim, o Gráfico 1 mostra que a síntese produzida resiste ao teste do ajuste do modelo realizado.

\section{Gráfico 1}

Teste do modelo ajustado para o cálculo dos efeitos da Emenda Constitucional 29/2000 e das variáveis contextuais sobre o percentual da receita aplicado na saúde pelos estados e DF - Brasil - 1998 - 2004

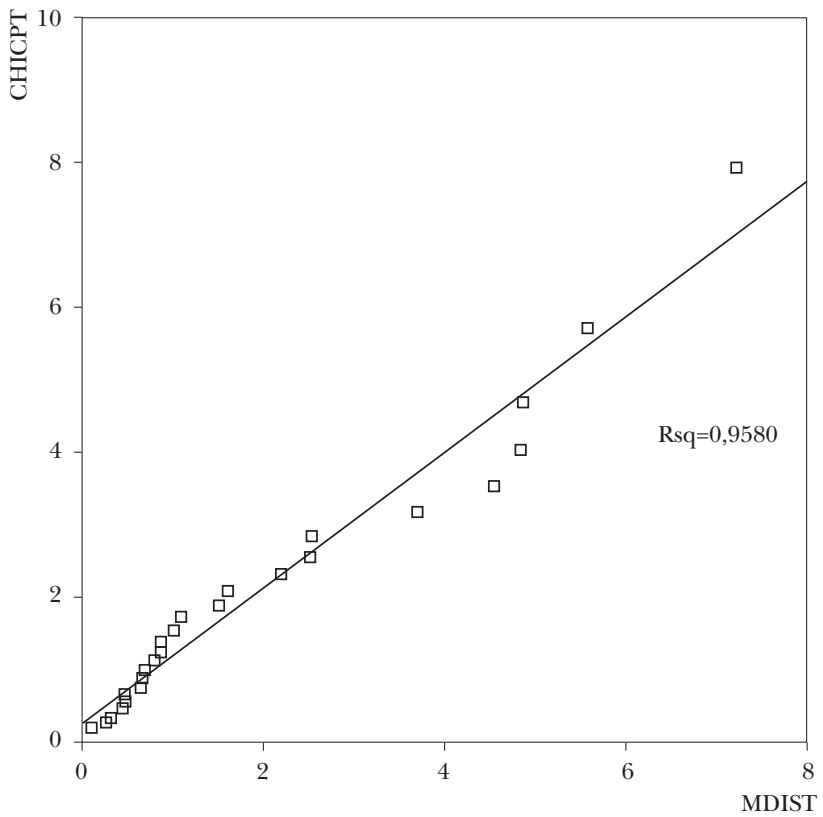

CHIPCT = distância entre os valores teóricos e os valores ajustados. $M D I S T$ = distância entre os valores observados e os valores ajustados. 
Os resultados permitem concluir que a EC n. 29 foi capaz de induzir os governadores a elevarem os percentuais da receita líquida comprometida com a saúde e que, individualmente, as variáveis selecionadas não conseguiram explicar as diferenças na adesão dos governadores à EC n. 29. Não se pode concluir, entretanto, que essas variáveis não tenham entrado no cálculo dos governadores para a tomada de decisão.

Tomando-se a capacidade de gasto, o desempenho econômico tributário e o comprometimento da receita com pessoal, argumenta-se que tais variáveis condicionam os graus de autonomia dos governadores para elevar a despesa com saúde e, dessa forma, são capazes de interferir nas escolhas dos governadores. Os resultados permitem concluir apenas que essa interferência não foi direta e, assim, passível de ser verificada com a metodologia adotada. Para saber em que medida tais variáveis condicionaram as escolhas dos

194 governadores, é necessário uma abordagem de natureza qualitativa que permita a reconstituição dos processos decisórios. A esse respeito, a análise realizada não se mostrou totalmente desprovida de importância à proporção que foi capaz de apontar que dois estados apresentaram comportamentos bem contrastantes e, nesse sentido, poderiam ser investigados numa abordagem qualitativa.

Com relação ao perfil ideológico do governador, o resultado encontrado não chega a surpreender, à medida que corrobora os resultados de diversos outros trabalhos. A escolha das demais variáveis tomou por base a literatura internacional que trata dos determinantes dos gastos com saúde e visou contribuir para um debate que, de fato, tem gerado mais perguntas que respostas. A fragilidade das bases teóricas dos determinantes dos gastos não tem permitido orientar adequadamente a escolha das variáveis e a compreensão dos mecanismos causais envolvidos (Gerdtham e Jönsson, 2000). 


\section{A EC n. 29 e o gasto das três esferas de governo com assistência à saúde}

Na seção anterior ficou evidenciado que a EC n. 29 conseguiu garantir maior compromisso dos estados com o financiamento do SUS, ainda que a maioria deles não tenha atingido, em 2004, o percentual estipulado para o comprometimento da receita com os gastos com saúde (12\%). Com efeito, a esfera estadual aumentou sua participação no gasto público com saúde (4,86 pontos percentuais), quando se comparam as médias dos períodos 1998-2000 e 2001-2004, tendo elevado sua participação de 17,91\% para 22,77\% (Tabela 1).

A União, mantendo a tendência de queda dos anos de 1990, reduz em 4,51 pontos percentuais sua participação entre os dois períodos analisados, passando de aproximadamente $56,91 \%$, antes da EC n. 29, para 52,40\%, depois dessa emenda.

O conjunto dos municípios apresentou uma discreta redução de menos de meio ponto percentual. É preciso esclarecer que, a despeito dessa diminuição na participação, as informações disponíveis indicam que o valor do gasto da esfera municipal cresceu no período. Acrescente-se que os municípios, em sua maioria, têm cumprido a EC n. 29. Em 2003, cerca de $86 \%$ deles gastavam com saúde mais de $15 \%$ de sua receita líquida (Campelli et al., 2007).

Constatou-se, portanto, que a EC n. 29 promoveu, de fato, uma mudança na participação dos entes federativos no financiamento da política de saúde do país e que, conforme esperado, a esfera estadual foi a que apresentou alteração mais significativa. Tais evidências sustentam o argumento de que um dos propósitos da EC n. 29 era desonerar o Executivo federal e repassar os encargos às esferas subnacionais, em particular, para os estados. 
Tabela 1:

Participação média das três esferas de governo no gasto público total com saúde (\%) Brasil - 1998/2000 (1) e 2001-2004

\begin{tabular}{|c|c|c|c|}
\hline Esferas de Governo & $1998 / 2000$ & $2001-2004$ & Diferença \\
\hline Federal & 56,91 & 52,40 & $-4,51$ \\
\hline Estadual & 17,91 & 22,77 & 4,86 \\
\hline Municipal & 25,19 & 24,82 & $-0,37$ \\
\hline Total & 100,00 & 100,00 & 0,00 \\
\hline
\end{tabular}

Fonte: Dados básicos: Sistema de Informações sobre Orçamentos Públicos em Saúde (SIOPS) 2000-2004. Disponível em: http// siops.datasus.gov.br. Acesso em Jul. de 2007.

(1) Foram considerados os gastos de 1998 e 2000.

Dois argumentos principais guiaram a análise dos efeitos 196 da EC n. 29 nas decisões alocativas dos governadores estaduais: primeiro, as instituições, entendidas como regras formais, orientam o cálculo e a interação dos atores, minimizando a incerteza dos resultados políticos; segundo, para investigar seus impactos, é preciso considerar que as escolhas refletem a interação entre instituições e o contexto das escolhas (Putnam, 1996; Tsebelis, 1998; Anastasia, 2002).

$\mathrm{O}$ estudo realizado corroborou o primeiro argumento, à medida que se constatou que a EC n. 29 induziu a grande maioria dos governadores a elevar a proporção de suas receitas comprometida com a saúde, reduzindo as incertezas quanto ao financiamento do SUS. O percentual médio da receita aplicado na saúde passou de 7,99\% no ano em que a EC n. 29 foi aprovada, para 11,29\% em 2004 (tabelas 1 e 2).

Com relação ao segundo argumento, constatou-se que as variáveis selecionadas para descrever o contexto das escolhas não se mostraram capazes, individualmente, de explicar as variações encontradas nas respostas dos governado- 
res. Ainda que possam compor o contexto das decisões, as influências sob estas, mediadas pelos mais diversos interesses e circunstâncias, não puderam ser captadas numa abordagem dessa natureza.

A compreensão dos condicionantes das diferenças encontradas nas trajetórias dos estados e, portanto, da complexa relação entre condicionantes e tomada de decisão aponta para uma agenda futura de estudos em que se busque, a partir de uma abordagem qualitativa, apreender a dinâmica dos processos políticos. Conforme apontado, o comportamento do Rio Grande do Sul, de um lado, e o do Amazonas, de outro, mostraram-se bastante contrastantes. Tal constatação sugere que esses estados poderiam ser selecionados para uma análise comparativa.

A análise da trajetória da EC n. 29 confirmou o argumento de que estados federativos não criam, necessariamente, obstáculos à atuação do governo central. Além de estabelecer o ritmo de tramitação da EG n. 29, o Executivo federal conseguiu fazer valer suas preferências quanto ao desenho dessa emenda. No entanto, a posição institucional dos governadores estaduais tem-lhes permitido definir o grau de adesão à EC n. 29.

Resguardados pela ausência de uma definição de ações e serviços de saúde no texto da EC n. 29, muitos governadores computaram como gasto com saúde despesas não classificadas como tal pela Portaria n. 2047 do Ministério da Saúde, a despeito dessa portaria ter por base resolução do Conselho Nacional de Saúde, que, por sua vez, resultou de discussões envolvendo as três esferas de governo.

A desconsideração dos governadores para com o Siops, denotando a resistência dos mesmos em tornar públicas as informações sobre contribuição de seus estados para o financiamento do SUS, constitui mais uma evidência do poder dos governadores de definir seu grau de adesão às propostas do Executivo federal. 
O estudo realizado lançou luzes sobre os desafios postos ao comando do gasto público e ao compartilhamento de responsabilidades pela engenharia federativa. Constatou-se que a EC n. 29 foi, de certa forma, bem-sucedida no sentido de impor uma dada direção aos gastos com a saúde e, dessa forma, em favorecer a coordenação federativa no financiamento do SUS. No entanto, ainda que a ação coletiva em países federativos possa ser favorecida por meio de regras, os efeitos plenos destas podem ser retardados ou, mesmo, não ser atingidos caso o consenso em torno delas mostre-se frágil (Dahl, 1990). No caso da EC n. 29, essa fragilidade manifesta-se nos percalços enfrentados tanto para regulamentá-la quanto para implementá-la.

A análise dos efeitos da EC n. 29 reafirmou a pertinência do argumento neoinstitucionalista de que as instituições não podem ser consideradas apenas como "coerções herdadas" e, portanto, exógenas ao processo político, mas que 198 atores racionais tendem a buscar participar da elaboração/ alteração das regras, de modo a favorecer as próprias escolhas (Tsebelis, 1998).

Conforme foi constatado, ao mesmo tempo que induziu o aumento dos gastos com saúde, a EC n. 29 passou a estimular outros jogos, envolvendo disputas relacionadas ao conceito de "ações e serviços de saúde" e à base de cálculo para a definição da participação da União. A regulamentação prevista foi uma brecha para que os representantes das esferas de governo passassem a agir estrategicamente de modo tanto a criar obstáculos à implementação quanto a promover ajustes no texto da EC n.29.

Os conflitos em torno da interpretação da base de cálculo dos recursos federais e do conceito de ações e serviços de saúde, as tentativas de "burlar" a EC n. 29, os problemas no preenchimento do Siops e os percalços sofridos pelo processo de regulamentação expõem as dificuldades do federalismo brasileiro em combinar a autonomia dos entes 
federados com a necessidade de coordenação política do financiamento do SUS e em compartilhar responsabilidades. Ainda que a constitucionalização de encargos tenha se mostrado um mecanismo de coordenação da ação coletiva no financiamento do SUS, ela colocou também novos dilemas. Corroborou-se, assim, o argumento de Pierson (1995) de que as relações entre os diferentes níveis de governo envolvem "mais que um cabo de guerra", admitindo jogos de competição, cooperação e acomodação.

Por fim, pode-se colocar que os percalços sofridos pelo processo de regulamentação da EC n. 29 juntamente com os resultados da análise dos efeitos dessa emenda sobre as decisões dos governadores, constituem mais uma evidência da fragilidade institucional brasileira em termos da capacidade de impor o cumprimento de regras.

\section{Fátima Beatriz Fortes}

é pesquisadora da Fundação João Pinheiro.

\section{Referências bibliográficas}

ANASTASIA, F. 2002. "Teoria democrática e o novo institucionalismo". Cadernos de Ciências Sociais, v.8, n.11, pp.31-46.

ARRETCHE, M. 2000. Estado federativo e políticas sociais: determinantes da descentralização. Rio de Janeiro: Revan.

; MARQUES, E. 2002. "Municipalização da saúde no Brasil: diferenças regionais, poder do voto e estratégias de governo”. Ciência e Saúde Coletiva, v.7, n.3, pp.455-79.

BLAIS, A. et al. 1993. "Do parties make a difference? Parties and the size of government in liberal democracies". American Journal of Political Science, v.37, n.1, pp.40-62.

BRASIL. 2000. "Emenda Constitucional n. 29, de 13 de setembro, que altera os arts. 34, 35, 156, 160, 167 e 198 da Constituição Federal e acrescenta artigo ao Ato das Disposições Constitucionais Transitórias, para assegurar os recursos mínimos para o financiamento das ações e serviços públicos de saúde”. Diário Oficial da República Federativa do Brasil, ano 138, n.178, pp.1-2, 14 set. 2000. Seção 1. 
CAMPELLI, M. G. R.; CALVO, M. C. M. 2007. "O cumprimento da Emenda Constitucional no Brasil”. Caderno de Saúde Pública, v.23, n.7, pp.1613-26.

CASTRO, M. M. M. 1993. "Raça e comportamento político". Dados, v.36, n.3, pp.469-91.

DAHL, R. A. 1990. Um prefácio à teoria democrática. Rio de Janeiro: Jorge Zahar.

DIAS, J. L. M. 1997. Federalismo, governos estaduais e políticas públicas: uma análise das instituições federais no Brasil. Rio de Janeiro, 192p. Tese de doutorado. Instituto Universitário de Pesquisas do Rio de Janeiro.

FAVERET, A. C. S. C. 2002. Federalismo fiscal e descentralização no Brasil: o financiamento da política de saúde na década de 90 e início dos anos 2000. Rio de Janeiro, 200p. Tese de doutorado. Instituto de Medicina Social da Universidade do Estado do Rio de Janeiro.

FORTES, F. B. C. T. P. 2008. Inovação institucional no contexto do federalismo brasileiro pós-1988: a emenda constitucional n. 29 de 2000 e os governos estaduais. Belo Horizonte, 198p. Tese de doutorado. Faculdade de Filosofia e Ciências Humanas da Universidade Federal de Minas Gerais.

FUNDAÇÃO JOÃO PINHEIRO. 1998. Finanças dos municípios mineiros: diversidade e indicadores. Belo Horizonte: Centro de Estudos Econômicos e Sociais.

GERDTHAM, U. G.; JÖNSSON, B. "International Comparisons of Health Expenditure: theory, data and econometric analysis". In: CULYER, A. J.; NEWHOUSE, J. P. (orgs.). 2000. Handbook of health economics. Amsterdam: North-Holland, pp.13-53.

HALL, P. A.; TAYLOR, R. C. R. 1996. "Political science and the three new institutionalisms". Political Studies, v.44, n.5, p. 936-57.

HOSMER, D. W.; LEMESHOW, S. 2000. Applied logistic regression. New York: Wiley.

LOPREATO, F. L. C. A situação financeira dos estados e a reforma tributária. Disponível em www.eco.unicamp.br/docprod/downarq. php?id=1745\&tp=a. Acesso em 26/12/2012.

MARQUES, R. M.; MENDES, A. 2005. "Os dilemas do financiamento do SUS no interior da seguridade social”. Economia e Sociedade, v.14, n.1 (24), pp.159-75.

MÉDICI, A. C. 1994. Economia e financiamento do setor saúde: balanços e perspectivas do processo de descentralização. São Paulo: Faculdade de Saúde Pública da Universidade de São Paulo.

MELO, C. R. F. 2000. "Partidos e migração partidária na Câmara dos Deputados”. Dados, v.43, n.2, pp.207-39. 
MENICUCCI, T. M. G. 2003. Público e privado na política de assistência à saúde no Brasil: atores, processos e trajetória. Belo Horizonte, 319p. Tese de doutorado. Faculdade de Filosofia e Ciências Humanas da Universidade Federal de Minas Gerais.

OLSON, M. 1999. A lógica da ação coletiva. São Paulo: Edusp

PIERSON, P. 1995. "Fragmented welfare states: federal institutions and the development of social policy". Governance, v.8, n.4, pp.449-78.

PIOLA, S. et al. 2000. "Financiamento das políticas sociais: o caso do Ministério da Saúde”. Revista do Serviço Público, ano 51, n.3, pp.75-100.

PUTNAM, R et al. 1996. Comunidade e democracia: a experiência da Itália moderna. Rio de Janeiro: FGV.

RAUDENBUSH, S. W.; BRYK, A. S. 2002. Hierarchical linear models: applications and data analysis methods. Thousand Oaks, CA: Sage.

REZENDE, F.; AFONSO, J. R. 2004. "A federação brasileira: desafios e perspectivas". In: REZENDE, F.; OLIVEIRA, F. A. (orgs.). Federalismo e integração econômica regional: desafios para o Mercosul. Rio de Janeiro: Konrad Adenauer Stiftung.

RIBEIRO, J. A. et al. 2007. "As novas configurações de antigos problemas: financiamento e gasto com ações e serviços públicos de saúde no Brasil”. Divulgação em Saúde para Debate, n.37, pp.21-43.

RIBEIRO, L. M. 2006. "Partidos políticos e gastos sociais nos municípios brasileiros (1996-2004)". Trabalho apresentado no V Encontro da Associação Brasileira de Ciência Política. Belo Horizonte.

RODRIGUES, G. A. 2003. "Ação político-partidária nas administrações municipais e seus reflexos sobre os gastos públicos em Santa Catarina”. Trabalho apresentado no XXVII Encontro Nacional da Anpocs. Caxambu.

SANTOS, L. 1994. Distribuição de competência no sistema único de saúde: o papel das três esferas de governo no SUS. Brasília: Organização Pan-Americana da Saúde; Escritório Regional da Organização Mundial da Saúde.

SERRA, J.; AFFONSO, J. R. R. 1999. "Federalismo fiscal à brasileira: algumas reflexões”. Revista do BNDES, v.6, n.12, pp.3-30.

SOUZA, C. 2005. "Federalismo, desenho constitucional e instituições federativas no Brasil pós-1988”. Revista de Sociologia e Política, Paraná, n.24, pp.105-21.

THELEN, K.; STEINMO, S. 1992. "Historical institutionalism in comparative politics”. In: STEINMO, S. et al. (orgs.) Structuring politics: historical institutionalism in comparative analysis. Cambridge: CUP.

TSEBELIS, G. 1998. Jogos ocultos: escolha racional no campo da política comparada. São Paulo: Edusp. 
UGÁ, M. A. D.; MARQUES, R. M. 2005. "O financiamento do SUS: trajetória, contexto, e constrangimentos”. In: LIMA, N. T. et al. (orgs.). Saúde e democracia: história e perspectivas do SUS. Rio de Janeiro: Fiocruz.

VIANA, A. L. et al. 2006. "Pesquisa para a tomada de decisão: um estudo de caso no Brasil". Cadernos de Saúde Pública, v.22, pp.557-67.

VIANNA, S. M. 2000. Revisitando a distribuição de encargos na saúde entre esferas de governo. Projeto BRA/97/013. Rio de Janeiro: IPEA.

WEAVER, K ; ROCKMAN, B. (orgs.). 1993. Do institutions matter? Government capabilities in the USA and abroad. Washington, D.C.: The Brookings Institution.

WHITEHEAD, M. 1991. Los conceptos y principios de la equidad en la salud. Washington, DC: Organización Panamericana de la Salud. 


\section{A EMENDA CONSTITUCIONAL N. 29 DE 2000 E OS GOVERNOS ESTADUAIS}

\section{FÁTIMA BEATRIZ FORTES}

Resumo: O objetivo deste artigo é investigar os efeitos da Emenda Constitucional n. 29, de 2000 (EC n. 29) nas decisões alocativas dos governadores estaduais referentes aos gastos com saúde. Os resultados dos modelos ajustados mostraram que a variável indicadora emenda para a aprovação da EC n. 29 mostrou-se altamente significativa, confirmando que sua aprovação induziu os governadores a elevarem o percentual da receita aplicado na saúde. Entre as variáveis de contexto, apenas a receita líquida per capita e o perfil ideológico do partido do governador mostraram-se significativas. No entanto, os resultados encontrados permitem afirmar que tais variáveis condicionam apenas marginalmente o efeito substantivo da EC n. 29 nos estados.

Palavras-chave: Emenda Constitucional n. 29; Gasto com Saúde; Coordenação Federativa; Decisões Alocativas dos Governos Estaduais. 


\section{CONSTITUTIONAL AMENDMENT 29 (EC N.29) OF 2000 AND THE DECISIONS OF STATE GOVERNORS}

Abstract: The purpose of this paper is to investigate the effects of Constitutional Amendment 29 (EC n.29), of 2000, on the decisions of state governors related to the allocation of funds for the health sector, aiming at identifying its conditioning factors. The results of the adjusted model showed that the variable amendment indicating the passing of EC n. 29 was highly significant, confirming that its passing induced governors to raise the revenue percentage invested in the health sector. Among context-related variables, just the net per capita revenue and the ideological profile of the governor's party were significant. However, the overall results allow to state that such variables only marginally condition the substantial effect of the Amendment on the states. What can be concluded is that the introduction of a rule such as EC n. 29 was capable of inducing governors to adopt behaviors despite the context-related variables considered herein.

Keywords: Constitutional Amendment 29; Expenditures on Health; Federative Coordination; Decisions of State Governors Related to The Allocation of Funds.

Recebido: 11/06/2010 Aprovado: 28/05/2012 